\title{
Urinary Lead Concentration Is an Independent Predictor of Cancer Mortality in the U.S. General Population
}

\author{
Sen $\mathrm{Li}^{1,2 * t}$, Jiaxin Wang ${ }^{1+}$, Biao Zhang ${ }^{3+}$, Yuan Liu${ }^{4}$, Tao Lu', Yuanyuan Shi', \\ Guangliang Shan ${ }^{3}$ and Ling Dong ${ }^{1 *}$
}

${ }^{1}$ School of Life Sciences, Beijing University of Chinese Medicine, Beijing, China, ${ }^{2}$ Department of Physiology, LKS Faculty of Medicine, University of Hong Kong, Hong Kong, Hong Kong, ${ }^{3}$ Department of Epidemiology and Statistics, School of Basic Medicine, Peking Union Medical College, Institute of Basic Medical Sciences, Chinese Academy of Medical Sciences, Beijing, China, ${ }^{4}$ Department of Biostatistics and Bioinformatics, Winship Cancer Institute, Emory University, Atlanta, GA, United States

\section{OPEN ACCESS}

Edited by:

Jianguang Ji,

Lund University, Sweden

Reviewed by:

Jerry Polesel,

Centro di Riferimento Oncologico di

Aviano (IRCCS), Italy

Jiping Yue,

University of Chicago, United States

*Correspondence:

Sen Li

senli@connect.hku.hk;

Ling Dong

dongling@bucm.edu.cn

these authors have contributed equally to this work.

Specialty section:

This article was submitted to Cancer Epidemiology and Prevention,

a section of the journal

Frontiers in Oncology

Received: 10 April 2018

Accepted: 18 June 2018

Published: 29 June 2018

Citation:

Li S, Wang J, Zhang B, Liu Y, Lu T,

Shi Y, Shan G and Dong L (2018) Urinary Lead Concentration Is an Independent Predictor of Cancer Mortality in the U.S. General Population.

Front. Oncol. 8:242.

doi: 10.3389/fonc.2018.00242
Lead is a ubiquitous pollutant that constitutes an environmental hazard worldwide. Although lead has been known as a carcinogenic factor in animal models, its role in human carcinogenesis is still a topic of debate with limited epidemiological evidence. Moreover, the association between urinary lead, as the most non-invasive and accessible way for lead measurement in human, and cancer mortality in general population has never been explored. We addressed this subject using continuous National Health and Nutrition Examination Survey 1999-2010 data and its Mortality Follow-Up Study. Of 5,316 subjects in study population, 161 participants died due to cancer. Cancerspecific mortality was associated with urinary lead levels after multivariable adjustment. Kaplan-Meier survival curve and cubic regression spline analyses indicated that high concentration of urinary lead exhibited significant association with raised death rate of cancer. Despite the marked decrease in environmental lead levels over the past three decades, lead exposure is still the significant determinant of cancer mortality in general population in U.S., and quantification of urinary lead may serve as a non-invasive approach to facilitate biomarker discovery and clinical translational research.

Keywords: urinary lead, cancer mortality, National Health and Nutrition Examination Survey, epidemiology, biomarker

\section{INTRODUCTION}

Lead is a ubiquitous environmental pollutant with a history of pollution for approximately 2,500 years (1). Lead can occur naturally, but its environmental presence is mainly from mining or historical use in paint and gasoline (2). Based on National Health and Nutrition Examination Survey (NHANES) data, the percentage of U.S. adults with blood lead concentration higher than $20 \mu \mathrm{g} / \mathrm{dL}$ reduced from $15 \%$ in NHANES II (1976-1980) to 0.6\% in NHANES III (1988-1994)

\footnotetext{
Abbreviations: NHANES, National Health and Nutrition Examination Survey; ICD-10, International Statistical Classification of Diseases, Injuries, and Causes of Death; NCHS, National Center for Health Statistics; NDI, National Death Index; ICP-MS, inductively coupled plasma-mass spectrometry; PIR, poverty income ratio; BMI, body mass index; cHR, crude hazard ratio; aHR, adjusted hazard ratio; CI, confidence interval; ALAD, delta-aminolevulinic acid dehydratase; CVD, cardiovascular disease; CLRD, chronic lower respiratory diseases; CeVD, cerebrovascular disease; $\mathrm{AD}$, Alzheimer's disease; Flu \& pneumonia, influenza and pneumonia.
} 
(3). The decreased blood lead concentration during late 1900s is attributed by reduction and elimination of lead in gasoline (4), restricted use of lead-based paints, and removal of lead solder from food cans $(5,6)$. However, the half-life of bone lead could be as much as 48.6 years, suggesting long-term effects of lead exposure on health and health disparities (7). Leadcontaining deteriorated paint and ceramic food vessel also make lead pollution a health problem (8). Moreover, removal of environmental heavy metals is with difficulty, because they cannot be chemically or biologically degraded, and are normally indestructible. Thus, lead constitutes an environmental hazard worldwide (9).

The chronic influences of lead exposure are still uncertain (3). Several epidemiological reports have linked high concentration of lead in human with a variety of diseases and disorders, including heart disease $(10,11)$, hypertension (12), renal function impairment (13), and cancer (14). Although lead has been known as a carcinogenic factor in animal models, its role in human carcinogenesis is still a topic of debate. Because of limited epidemiological evidence, the IARC Working Group categorized inorganic lead compounds as "probably" human carcinogens (group 2A) (15). Recently, several epidemiological studies have illustrated the association of blood lead concentration and death rate due to cancer in numerous populations, including U.S. adults $(14,16)$, lead-exposed workers in South Korea (17) and Australia (18). However, whether urinary lead, as the most non-invasive and accessible way for lead measurement in human, is associated with cancer mortality has never been explored in the general population. Here, we demonstrate a significant association between urinary lead concentration and cancer mortality using data from NHANES and its Mortality Follow-Up Study.

\section{MATERIALS AND METHODS}

\section{Study Population}

Continuous NHANES is a nationwide complex survey to collect and evaluate health and nutrition condition of the non-institutional civilian U.S. population $(19,20,21)$. The survey data are released by National Center for Health Statistics biannually for public use since 1999, and NHANES has been approved by National Health Statistics Institutional Review Board. In this study, data from six NHANES survey cycles (1999-2010) and the NHANES (1999-2010) publicly available Linked Mortality File were employed to study the association between urinary lead concentration and cancer-specific mortality. NHANES Linked Mortality File is a follow-up study, in which the NHANES data are linked with National Death Index death certificate records. Present analyses were restricted to participants with age $\geq 40$ years at baseline according to previous publication (16). Of the 19,968 participants with age $\geq 40$ years, 6,490 (32.5\%) had urinary lead data at the time of the examination. Four participants were excluded due to the inadequate information of follow-up. We also excluded 1,170 sampling persons who had insufficient information for other variables, leading to a final population of 5,316 participants in this study (Figure S1 in Supplementary Material). The median length of follow-up was 66 months, and 667 all-cause deaths (401 males and 266 females) and 161 cancer-specific deaths (100 males and 61 females) were recorded during follow-up. Analyses involving nine urinary metals further excluded participants with data missing for any of these nine metals, leading to a study population of 3,757 adults (Figure S1 in Supplementary Material).

\section{Cancer-Specific Mortality}

Deaths due to malignant neoplasm were identified according to the leading causes of death as indicated in the public-use linked mortality file, which is based on the International Statistical Classification of Diseases, Injuries, and Causes of Death (ICD-10) guidelines (ICD-10 codes C00-C97). Participants with no information on death were deemed as alive and censored at the end of follow-up (December 31, 2011). For analysis of cancer-related mortality, follow-ups for participants with other leading causes of death were censored at the age when they died.

\section{Urinary Metal Measurement}

Urinary samples were collected from eligible participants, and analysis was performed at Centers for Disease Control and Prevention. Samples were loaded into inductively coupled plasma-mass spectrometry, and urinary barium $(\mathrm{Ba})$, cadmium $(\mathrm{Cd})$, cobalt $(\mathrm{Co})$, cesium $(\mathrm{Cs})$, molybdenum $(\mathrm{Mo})$, lead $(\mathrm{Pb})$, thallium (TI), tungsten $(\mathrm{W})$, and uranium $(\mathrm{U})$ were measured. The detailed methodology is available in NHANES Laboratory Procedures Manual (22). Beryllium (Be), antimony (Sb), and platinum $(\mathrm{Pt})$ were not included in this study because their readouts from a substantial number of measurements were below the limit of detection. In the analysis using urinary lead levels as a continuous variable, urinary lead concentration was log transformed because of their skewed distribution.

\section{Other Variables}

The associations between urinary lead concentration and allcause or cancer-specific mortality were adjusted for a series of potential confounding factors: age in years at baseline examination (40-49, 50-59, 60-69, or $\geq 70$ ), race (Non-Hispanic white, Non-Hispanic black or others), education ( $<$ high school, high school or $>$ high school), poverty income ratio (PIR; $<1$, $1 \leq \mathrm{PIR} \leq$ median or $>$ median, where medians were computed based on PIR $\geq 1$ for each of the six data cycles), body mass index (BMI; $<25$ or $\geq 25 \mathrm{~kg} / \mathrm{m}^{2}$, where BMI $\geq 25 \mathrm{~kg} / \mathrm{m}^{2}$ indicates overweight based on NIH health guidelines), smoking status (yes or no, based on the question "Have you smoked at least 100 cigarettes in your entire life?"), alcohol usage (yes or no, based on the question "In any one year, have you had at least 12 drinks of any type of alcoholic beverage?"), diabetes status (yes or no, based on the question "Have you ever been told by a doctor or health professional that you have diabetes or sugar diabetes?"), and hypertension status (yes or no, based on the question "Have you ever been told by a doctor or other health professional that you had hypertension, also called high blood pressure?"). Moreover, urinary creatinine concentration was $\log$ transformed, and adjusted as an independent variable 
to account for urine dilution as suggested by other studies (23-25). To identify the relationship between urinary lead and blood lead, the ratio of urinary lead concentration $(\mu \mathrm{g} / \mathrm{L})$ to urinary creatinine concentration $(\mathrm{mg} / \mathrm{dL}$ ) (correction for urine dilution) was log transformed and applied in the correlation analysis with log transformed urinary blood lead concentration $(\mu \mathrm{g} / \mathrm{dL})$ as suggested (26).

\section{Statistical Analysis}

Specific sample weights for subsample with urinary multianalyte profile are employed to account for the complex sampling design following the NHANES Analytic and Reporting Guidelines. The weighted characteristics were calculated based on overall data, and data stratified by urinary lead levels $(\leq 0.40$, $0.41-0.73,0.74-1.26$ and $>1.26 \mu \mathrm{g} / \mathrm{L}$ ) or mortality status. Possible statistical differences of various variables at different urinary lead quartiles were accessed using the Rao-Scott chi-square test. In this study, the term "mortality" generally refers to cumulative mortality (i.e., prevalence of death). In addition, we also calculated mortality rates per 1,000 personyears, where the number of person-years was calculated as the time between baseline examination and date of death or the termination date of the study (December 31, 2011) (27). The association between urinary lead concentration and cancerspecific death rate was examined by Cox proportional hazards regression using "PHREG" procedure. In analyses for all-cause and cancer-specific mortalities, interaction of urinary metal levels with follow-up time was incorporated to examine proportional hazard assumption, and this interaction was leaved in the model if the assumption was violated in order to model non-proportional hazards as suggested (28). By comparing the first quartile of urinary lead levels, the hazard ratio, 95\% confidence intervals (CIs), and $P_{\text {trend }}$ for the risk of cancer death rate in regard to urinary lead quartiles were calculated. In addition to Cox regression, Fine and Gray regression was performed to account for death from other causes as competing events (29). The direct adjusted Kaplan-Meyer curves were generated using "DIRADJ" option. To improve normality, urinary lead levels were log transformed in the analysis of dose-response relationship for urinary lead levels and cancer-specific death rate, which was examined by three-knot restricted cubic splines (RCSs) using publicly available SAS macro (30). Covariateadjustment for Cox hazards regression was employed for RCS analysis. SAS 9.4 software (SAS Institute Inc., Cary, NC, USA) was used to perform statistical analyses. Correlation structure of nine urinary metals was produced in $\mathrm{R}$ using the corrplot package.

\section{RESULTS}

Demographics of overall study population and subpopulations by urinary lead levels were demonstrated in Table 1. The sample size was $1,363,1,307,1,321$, and 1,325 by urinary lead categories $\leq 0.40,0.41-0.73,0.74-1.26$, and $>1.26 \mu \mathrm{g} / \mathrm{L}$, respectively, which was quartiles of distribution of urinary lead. Comparing to low urinary lead levels $(\leq 0.40 \mu \mathrm{g} / \mathrm{L})$, participants with high urinary lead $(>1.26 \mu \mathrm{g} / \mathrm{L})$ were more likely to be males, $\geq 70$ years old, non-white ethnicity, to have less education, income below median, to be cigarette- and alcohol-users, and to present no history of hypertension. Moreover, urinary lead levels were correlated with all-cause mortality $(P<0.01)$. Among all the nine underlying causes of death included in NHANES mortality study, urinary lead levels were only significantly associated with cancer mortality $(P<0.01)$ (Table 1$)$. In addition to cumulative mortality, we also calculated mortality rates for each quartile of the urinary lead concentration distribution. For all-cause mortality, mortality rates among participants with quartile 1, 2, 3, and 4 of urinary lead levels were 17.97, 19.45, 20.37, and 25.72 per 1,000 person-years, respectively. For cancer-specific mortality, mortality rates for quartile 1, 2, 3, and 4 of urinary lead levels were $2.89,4.25,5.35$, and 7.44 , respectively. It is of note that moderately strong positive relationship between urinary and blood lead concentration was revealed by correlation analyses in the analysis populations (Figure 1). We next investigated the possible correlation between mortality and other covariates and found that cancer mortality was correlated with age, education level, PIR and smoking status while all-cause mortality was associated with all the covariates listed in Table 2.

We next calculated HRs from Cox models for all-cause and cancer-specific mortality by employing urinary lead quartiles as an independent variable (Table 3). For all-cause mortality, subjects in the highest urinary lead quartile exhibited a HR of 1.79 (95\% CI $=1.15-2.78 ; P<0.01)$, compared with participants with urinary lead below $0.40 \mu \mathrm{g} / \mathrm{L}$ after fully adjusting the covariates. Cancer-specific mortality was also associated with urinary lead levels after multivariable adjustment with adjusted HRs of 6.60 (95\% CI $=2.37-18.37 ; P<0.01)$. Trend analyses indicated significant results for the risk of both all-cause and cancer-specific mortality in regard to urinary lead levels $\left(P_{\text {Trend }}<0.01\right)$. Similar results were observed in a subsample excluding subjects who were diagnosed with cancer at baseline and die due to non-cancer causes (Table S1 in Supplementary Material). Furthermore, sex-stratified analysis indicated similar associations in both genders (Table S2 in Supplementary Material). In addition, analysis in a population of participants with age $\geq 20$ years showed consistent results in Cox models (Table S3 in Supplementary Material). We next used the Fine-Gray competing risks method to estimate the association between urinary lead levels and cancer mortality after adjusting for covariates and accounting for potential bias caused by the competing risk of death from other causes, which indicated identical results $\left(P_{\text {Trend }}<0.01\right)$ with Cox models. In the overall study population (Figure S1 in Supplementary Material), 10-year survival was estimated by Kaplan-Meier curves for quintiles of the urinary lead (Figure 2A), and high levels of urinary lead were significantly associated with elevated mortality $\left(P_{\text {Trend }}<0.01\right)$. The dose-response relationship of urinary lead levels and cancer death rate was further studied in subjects with age over 40 years using log-transformed urinary lead concentration to model proportional hazards with a threeknot cubic regression spline (Figure 2B), which allows the shape of the relationship between the exposure and outcome to be flexible and not inherently linear. The result represented 
TABLE 1 | Weighted characteristics of the study population by urinary lead level-NHANES 1999-2010.

\begin{tabular}{|c|c|c|c|c|c|c|c|c|c|c|c|c|c|c|c|c|c|}
\hline \multirow[b]{3}{*}{ Variable } & \multirow[b]{3}{*}{ Status } & & & & \multicolumn{12}{|c|}{ Urinary lead level $(\mu \mathrm{g} / \mathrm{L})$} & \multirow[b]{3}{*}{$P$ value } \\
\hline & & \multicolumn{3}{|c|}{ Overall } & \multicolumn{3}{|c|}{$\leq 0.40$} & \multicolumn{3}{|c|}{$0.41-0.73$} & \multicolumn{3}{|c|}{$0.74-1.26$} & \multicolumn{3}{|c|}{$>1.26$} & \\
\hline & & $N$ & $\%$ & SE & $N$ & $\%$ & SE & $N$ & $\%$ & SE & $N$ & $\%$ & SE & $N$ & $\%$ & SE & \\
\hline \multirow[t]{2}{*}{ Gender } & Male & 2,694 & 47.72 & 0.75 & 473 & 31.59 & 1.40 & 614 & 46.54 & 1.77 & 718 & 53.81 & 1.48 & 889 & 65.22 & 1.48 & $<0.01$ \\
\hline & Female & 2,622 & 52.28 & 0.75 & 890 & 68.41 & 1.40 & 693 & 53.46 & 1.77 & 603 & 46.19 & 1.48 & 436 & 34.78 & 1.48 & \\
\hline \multirow[t]{4}{*}{ Age } & 40-49 years & 1,452 & 35.38 & 1.04 & 421 & 38.43 & 1.92 & 344 & 34.47 & 1.69 & 366 & 36.14 & 1.77 & 321 & 31.18 & 2.05 & 0.05 \\
\hline & $50-59$ years & 1,104 & 28.17 & 0.89 & 283 & 27.49 & 1.39 & 277 & 28.09 & 1.58 & 291 & 28.81 & 1.64 & 253 & 28.49 & 1.93 & \\
\hline & 60-69 years & 1,298 & 18.51 & 0.77 & 317 & 18.29 & 1.34 & 331 & 19.89 & 1.54 & 303 & 16.42 & 1.28 & 347 & 19.63 & 1.31 & \\
\hline & $\geq 70$ years & 1,462 & 17.94 & 0.71 & 342 & 15.80 & 1.20 & 355 & 17.54 & 1.08 & 361 & 18.63 & 1.07 & 404 & 20.70 & 1.29 & \\
\hline \multirow[t]{3}{*}{ Race } & White & 2,867 & 77.72 & 1.22 & 844 & 82.79 & 1.30 & 711 & 77.61 & 1.61 & 711 & 77.23 & 1.85 & 601 & 71.12 & 1.75 & $<0.01$ \\
\hline & Black & 1,024 & 9.75 & 0.72 & 172 & 6.08 & 0.64 & 252 & 10.07 & 0.89 & 275 & 10.50 & 1.02 & 325 & 13.75 & 1.27 & \\
\hline & Others & 1,425 & 12.53 & 0.99 & 347 & 11.13 & 1.10 & 344 & 12.32 & 1.25 & 335 & 12.27 & 1.45 & 399 & 15.13 & 1.30 & \\
\hline \multirow[t]{3}{*}{ Education } & $<$ High school & 1,699 & 19.41 & 0.91 & 355 & 16.00 & 1.40 & 376 & 17.08 & 1.43 & 445 & 22.12 & 1.55 & 523 & 23.96 & 1.66 & $<0.01$ \\
\hline & $=$ High school & 1,276 & 26.72 & 0.72 & 327 & 25.10 & 1.32 & 331 & 27.39 & 1.55 & 313 & 27.31 & 1.53 & 305 & 27.55 & 1.93 & \\
\hline & >High school & 2,341 & 53.86 & 1.13 & 681 & 58.90 & 1.85 & 600 & 55.53 & 1.71 & 563 & 50.56 & 1.83 & 497 & 48.49 & 1.98 & \\
\hline \multirow[t]{3}{*}{ PIR } & $<1$ & 859 & 10.07 & 0.52 & 199 & 8.62 & 0.85 & 191 & 8.73 & 0.79 & 203 & 10.81 & 0.94 & 266 & 12.90 & 0.96 & $<0.01$ \\
\hline & $1 \leq \mathrm{PIR} \leq$ median & 1,988 & 29.08 & 0.89 & 477 & 27.05 & 1.57 & 475 & 28.46 & 1.42 & 511 & 30.28 & 1.79 & 525 & 31.35 & 1.71 & \\
\hline & $>$ Median & 2,469 & 60.85 & 1.14 & 687 & 64.32 & 1.89 & 641 & 62.82 & 1.63 & 607 & 58.91 & 1.92 & 534 & 55.74 & 2.01 & \\
\hline BMl & $\geq 25$ & 3,916 & 71.76 & 0.93 & 967 & 67.46 & 1.64 & 962 & 72.82 & 1.63 & 1,008 & 74.50 & 1.47 & 979 & 73.46 & 1.53 & $<0.01$ \\
\hline Smoking & Yes & 2,797 & 52.86 & 0.99 & 597 & 45.07 & 1.84 & 633 & 48.30 & 1.88 & 740 & 58.04 & 1.53 & 827 & 63.50 & 1.97 & $<0.01$ \\
\hline Alcohol use & Yes & 3,603 & 71.34 & 1.06 & 836 & 65.51 & 1.79 & 843 & 69.13 & 1.67 & 940 & 75.63 & 1.41 & 984 & 77.35 & 1.51 & $<0.01$ \\
\hline Diabetes & Yes & 821 & 10.76 & 0.45 & 231 & 10.77 & 0.95 & 217 & 12.20 & 0.98 & 204 & 10.68 & 0.85 & 169 & 9.09 & 0.89 & 0.17 \\
\hline Hypertension & Yes & 2,380 & 39.07 & 0.99 & 664 & 42.42 & 1.88 & 621 & 39.98 & 1.73 & 570 & 37.51 & 1.55 & 525 & 34.98 & 1.72 & 0.01 \\
\hline \multirow[t]{10}{*}{ Mortality } & All-cause & 667 & 9.01 & 0.50 & 137 & 7.62 & 0.70 & 142 & 7.68 & 0.79 & 160 & 8.86 & 0.87 & 228 & 12.79 & 1.20 & $<0.01$ \\
\hline & CVD & 145 & 1.80 & 0.20 & 31 & 1.64 & 0.37 & 38 & 2.14 & 0.41 & 33 & 1.65 & 0.36 & 43 & 1.79 & 0.35 & 0.73 \\
\hline & Cancer & 161 & 2.35 & 0.23 & 22 & 1.62 & 0.39 & 31 & 1.76 & 0.47 & 42 & 2.53 & 0.48 & 66 & 3.89 & 0.60 & $<0.01$ \\
\hline & CLRD & 41 & 0.68 & 0.12 & 8 & 0.48 & 0.18 & 5 & 0.35 & 0.17 & 12 & 0.82 & 0.28 & 16 & 1.19 & 0.37 & 0.10 \\
\hline & Accidents & 27 & 0.52 & 0.12 & 5 & 0.41 & 0.22 & 4 & 0.35 & 0.22 & 3 & 0.37 & 0.22 & 15 & 1.05 & 0.38 & 0.22 \\
\hline & CeVD & 39 & 0.53 & 0.09 & 7 & 0.41 & 0.18 & 11 & 0.61 & 0.21 & 9 & 0.37 & 0.15 & 12 & 0.80 & 0.24 & 0.43 \\
\hline & $A D$ & 16 & 0.22 & 0.07 & 5 & 0.25 & 0.13 & 2 & 0.12 & 0.09 & 3 & 0.16 & 0.10 & 6 & 0.38 & 0.17 & 0.48 \\
\hline & Diabetes & 21 & 0.20 & 0.05 & 5 & 0.31 & 0.14 & 4 & 0.12 & 0.06 & 6 & 0.17 & 0.08 & 6 & 0.20 & 0.10 & 0.49 \\
\hline & Flu \& pneumonia & 13 & 0.13 & 0.04 & 2 & 0.08 & 0.06 & 5 & 0.14 & 0.07 & 3 & 0.19 & 0.11 & 3 & 0.11 & 0.08 & 0.79 \\
\hline & Kidney disease & 14 & 0.10 & 0.03 & 2 & 0.03 & 0.02 & 2 & 0.04 & 0.03 & 6 & 0.17 & 0.08 & 4 & 0.17 & 0.09 & 0.12 \\
\hline
\end{tabular}

N, number; \%, weighted percent; NHANES, National Health and Nutrition Examination Survey; CVD, cardiovascular disease; CLRD, chronic lower respiratory diseases; CeVD, cerebrovascular disease; $A D$, Alzheimer's disease; Flu \& pneumonia, influenza and pneumonia; PIR, poverty income ratio; BMI, body mass index.

covariate-adjusted relative hazards with a referent level of fifth percentile of urinary lead distribution. The spline analysis showed that the relative hazards of cancer-specific mortality generally increased with urinary lead concentration, and lower bound of $95 \%$ CI of the relative hazard exceeded reference line (relative hazard $=1$ ) at a urinary lead concentration of roughly $1.45 \mu \mathrm{g} / \mathrm{L}$.

Considering that toxic metal exposure may occur with relatively high level of concordance, sensitivity analyses were performed for a panel of nine urinary metals in a subsample (Table 4). Besides the association between urinary lead levels and cancer mortality, our result further identified urinary cadmium levels as a risk factor $\left(P_{\text {trend }}<0.01\right)$ (Table 4). As expected, correlation analysis indicated that any pair of the nine metals was positively correlated $(P<0.01)$ (Figure 3 ). Due to the moderate positive relationship $(r=0.56)$ between urinary lead and cadmium, we next studied whether urinary lead levels could serve as a surrogate marker of urinary cadmium levels and were of no separate significance. Interestingly, urinary lead levels were persistently associated with cancer mortality after adjusting log transformed urinary cadmium concentration as confounder $\left(P_{\text {trend }}<0.05\right)$. In addition, a multiplicative interaction term between urinary cadmium and lead levels was entered into the main model, which showed non-significant result $\left(P_{\text {interaction }}=0.35\right)$. After categorizing urinary cadmium and lead above and below the median, relative risk (RR)-based analysis was performed, which indicated marginally increased $\mathrm{RR}$ for only cadmium above the median $\left(\mathrm{RR}_{\text {adjusted }}=1.87\right.$; $95 \% \mathrm{CI}=0.74-4.71 ; P=0.19)$ or only lead above the median $\left(\mathrm{RR}_{\text {adjusted }}=1.78 ; 95 \% \mathrm{CI}=0.72-4.45 ; P=0.22\right)$, but a significantly higher RR for cancer mortality in participants with both cadmium and lead above the median $\left(\mathrm{RR}_{\text {adjusted }}=3.22 ; 95 \%\right.$ $\mathrm{CI}=1.41-7.35 ; P<0.01)$ when setting participants with both cadmium and lead below median as reference. In consistent with this analysis, participants with only cadmium, only lead, or both metals above the median showed higher incidences of cancer mortality $(2.18 \pm 0.98,1.69 \pm 0.65$, and $2.70 \pm 0.48$, respectively) (Figure 4). 

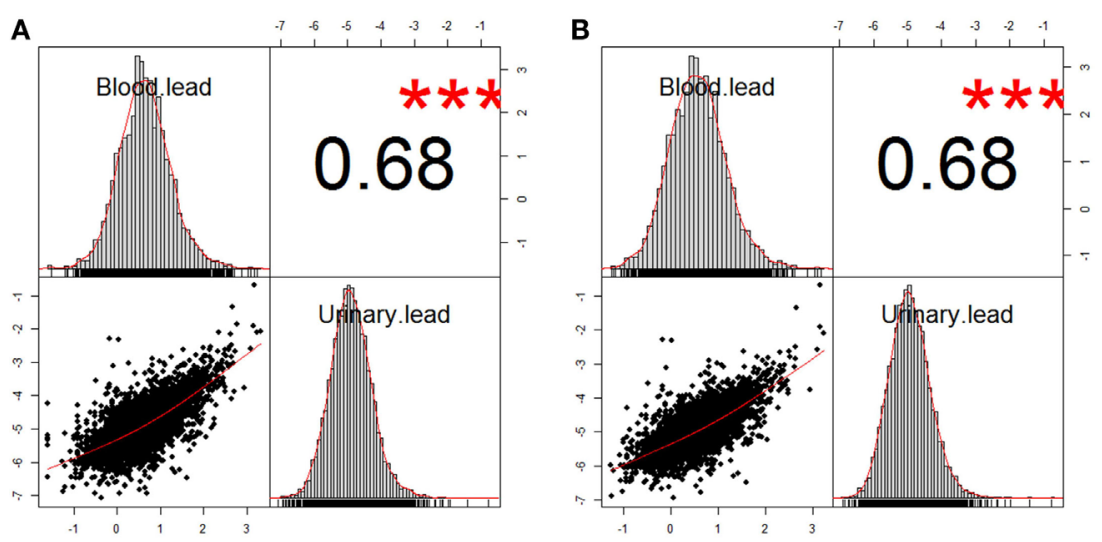

FIGURE 1 | Correlation between blood lead and urinary lead in two analysis populations. (A) $n=5,193$ after excluding participants with missing data of blood lead concentration from study population 1. (B) $n=3,677$ after excluding participants with missing data of blood lead concentration from study population 2 . The information about study population 1 and 2 can be found in Figure S1 in Supplementary Material. The correlation coefficients of both analysis populations were 0.68 , and ${ }^{* *}$ denotes $P<0.01$.

TABLE 2 | Weighted characteristics of the study population by mortality status-NHANES 1999-2010.

\begin{tabular}{|c|c|c|c|c|c|c|c|c|c|c|c|c|c|c|c|}
\hline \multirow[b]{3}{*}{ Variable } & \multirow[b]{3}{*}{ Status } & \multicolumn{6}{|c|}{ All-cause mortality } & \multicolumn{7}{|c|}{ Cancer mortality } & \multirow[b]{3}{*}{$P$ value } \\
\hline & & \multicolumn{3}{|c|}{ Yes } & \multicolumn{3}{|c|}{ No } & \multirow[b]{2}{*}{$P$ value } & \multicolumn{3}{|c|}{ Yes } & \multicolumn{3}{|c|}{ No } & \\
\hline & & $N$ & $\%$ & SE & $N$ & $\%$ & SE & & $N$ & $\%$ & SE & $N$ & $\%$ & SE & \\
\hline \multirow[t]{2}{*}{ Gender } & Male & 401 & 52.60 & 2.29 & 2,293 & 47.24 & 0.81 & 0.03 & 100 & 54.13 & 4.69 & 2,594 & 47.57 & 0.77 & 0.18 \\
\hline & Female & 266 & 47.40 & 2.29 & 2,356 & 52.76 & 0.81 & & 61 & 45.87 & 4.69 & 2,561 & 52.43 & 0.77 & \\
\hline \multirow[t]{4}{*}{ Age } & 40-49 years & 41 & 9.38 & 1.72 & 1,411 & 37.96 & 1.12 & $<0.01$ & 13 & 9.82 & 3.35 & 1,439 & 36.00 & 1.06 & $<0.01$ \\
\hline & 50-59 years & 64 & 17.58 & 2.25 & 1,040 & 29.22 & 0.95 & & 19 & 22.58 & 4.58 & 1,085 & 28.30 & 0.91 & \\
\hline & 60-69 years & 138 & 19.03 & 1.91 & 1,160 & 18.46 & 0.80 & & 44 & 27.47 & 4.98 & 1,254 & 18.29 & 0.78 & \\
\hline & $>70$ years & 424 & 54.01 & 2.60 & 1,038 & 14.37 & 0.68 & & 85 & 40.13 & 5.03 & 1,377 & 17.41 & 0.71 & \\
\hline \multirow[t]{3}{*}{ Race } & White & 408 & 78.87 & 1.84 & 2,459 & 77.61 & 1.27 & 0.01 & 96 & 81.53 & 2.77 & 2,771 & 77.63 & 1.23 & 0.14 \\
\hline & Black & 139 & 11.97 & 1.31 & 885 & 9.53 & 0.73 & & 32 & 10.03 & 1.76 & 992 & 9.74 & 0.72 & \\
\hline & Others & 120 & 9.16 & 1.54 & 1,305 & 12.87 & 1.01 & & 33 & 8.44 & 1.98 & 1,392 & 12.63 & 1.00 & \\
\hline \multirow[t]{3}{*}{ Education } & $<$ High school & 299 & 37.01 & 2.71 & 1,400 & 17.67 & 0.86 & $<0.01$ & 68 & 35.63 & 5.91 & 1,631 & 19.02 & 0.91 & $<0.01$ \\
\hline & $=$ High school & 164 & 28.06 & 1.93 & 1,112 & 26.59 & 0.79 & & 45 & 31.31 & 4.54 & 1,231 & 26.61 & 0.73 & \\
\hline & > High school & 204 & 34.94 & 2.67 & 2,137 & 55.74 & 1.12 & & 48 & 33.06 & 5.50 & 2,293 & 54.36 & 1.11 & \\
\hline \multirow[t]{3}{*}{ PIR } & $<1$ & 132 & 15.39 & 1.80 & 727 & 9.54 & 0.53 & $<0.01$ & 23 & 9.07 & 1.79 & 836 & 10.09 & 0.52 & $<0.01$ \\
\hline & $1 \leq \mathrm{PIR} \leq$ median & 321 & 45.73 & 2.72 & 1,667 & 27.43 & 0.93 & & 77 & 43.16 & 5.53 & 1,911 & 28.74 & 0.92 & \\
\hline & >Median & 214 & 38.88 & 2.66 & 2,255 & 63.02 & 1.16 & & 61 & 47.76 & 5.36 & 2,408 & 61.16 & 1.17 & \\
\hline BMl & $\geq 25$ & 440 & 65.61 & 2.42 & 3,476 & 72.37 & 1.00 & $<0.01$ & 111 & 67.07 & 4.74 & 3,805 & 71.88 & 0.96 & 0.31 \\
\hline Smoking & Yes & 410 & 64.54 & 1.97 & 2,387 & 51.71 & 1.05 & $<0.01$ & 112 & 74.15 & 4.56 & 2,685 & 52.35 & 1.01 & $<0.01$ \\
\hline Alcohol use & Yes & 441 & 65.64 & 2.53 & 3,162 & 71.90 & 1.07 & $<0.01$ & 122 & 77.70 & 4.62 & 3,481 & 71.19 & 1.05 & 0.19 \\
\hline Diabetes & Yes & 160 & 19.92 & 1.77 & 661 & 9.85 & 0.46 & $<0.01$ & 31 & 14.66 & 2.79 & 790 & 10.66 & 0.46 & 0.12 \\
\hline High blood pressure & Yes & 370 & 54.08 & 2.70 & 2,010 & 37.58 & 1.11 & $<0.01$ & 84 & 44.68 & 4.75 & 2,296 & 38.93 & 1.01 & 0.23 \\
\hline
\end{tabular}

N, number; \%, weighted percent; NHANES, National Health and Nutrition Examination Survey; PIR, poverty income ratio; BMI, body mass index.

\section{DISCUSSION}

Many metal ions are essential for human as trace elements, but they could be toxic at higher concentration. Lead is a ubiquitous environmental pollutant that can be found in lead-based paint and varnish, lead-using industries, lead solder, and leaded gasoline. Lead has various routes to enter the human body. For instance, lead particles from deteriorating lead-based paint or housing renovation adhere to food and therefore, can be ingested by humans. Industries that use lead in manufacturing can result in lead-polluted air and soil, thereby contaminating nearby animals and plants, which can transfer lead to humans via the food chain. Drinking water can also be contaminated by lead in plumbing solder. As a multitargeted toxicant, lead affects various systems, including cardiovascular, renal, and nervous systems with adverse impacts. The possible association between 
TABLE 3 | Hazard ratio for all-cause and cancer mortality by urinary lead levelNHANES 1999-2010.

\begin{tabular}{|c|c|c|c|c|}
\hline $\begin{array}{l}\text { Urinary lead } \\
\text { level ( } \mu \mathrm{g} / \mathrm{L})\end{array}$ & $N$ & cHR (95\% Cl) & aHR $(95 \% \mathrm{Cl})^{\mathrm{a}}$ & aHR $(95 \% \mathrm{Cl})^{\mathrm{b}}$ \\
\hline \multicolumn{5}{|c|}{ All-cause mortality } \\
\hline$\leq 0.40$ & 137 & 1.00 & 1.00 & 1.00 \\
\hline $0.41-0.73$ & 142 & $1.21(0.94-1.57)$ & $1.59(1.20-2.11)$ & 1.22 (0.92-1.62) \\
\hline $0.74-1.26$ & 160 & $1.40(1.02-1.91)$ & 2.05 (1.45-2.91) & 1.40 (0.99-1.99) \\
\hline$>1.26$ & 228 & 1.93 (1.32-2.83) & 3.15 (2.05-4.83) & $1.79(1.15-2.78)$ \\
\hline$P$ for trend & & $<0.01$ & $<0.01$ & $<0.01$ \\
\hline \multicolumn{5}{|c|}{ Cancer mortality } \\
\hline$\leq 0.40$ & 22 & 1.00 & 1.00 & 1.00 \\
\hline $0.41-0.73$ & 31 & 2.32 (1.23-4.39) & $2.79(1.42-5.48)$ & 2.05 (1.03-4.05) \\
\hline $0.74-1.26$ & 42 & $4.26(1.97-9.20)$ & $5.52(2.40-12.68)$ & 3.68 (1.58-8.57) \\
\hline$>1.26$ & 66 & 8.51 (3.42-21.16) & 11.83 (4.38-31.93) & $6.60(2.37-18.37)$ \\
\hline$P$ for trend & & $<0.01$ & $<0.01$ & $<0.01$ \\
\hline
\end{tabular}

cHR, crude hazard ratio; aHR, adjusted hazard ratio; $\mathrm{Cl}$, confidence interval; $\mathrm{N}$, number of deaths; NHANES, National Health and Nutrition Examination Survey; BMI, body mass index; PIR, poverty income ratio.

${ }^{a}$ Model was adjusted for creatinine (a marker of urine dilution).

${ }^{b}$ Model was adjusted for creatinine, sex, age, education, race, PIR, BMI, smoking

status, alcohol-use status, diabetes status, and high blood pressure status.

lead concentration in human and cancer-related death rate has also been reported in general population and occupational cohorts, although the conclusion is still plausible. Moreover, no previous work has investigated the relationship between urinary lead and cancer mortality while several studies have examined associations with blood lead using NHANES data that provide enough sociodemographic information to adjust for potential covariates. The analysis using NHANES II (1976-1980) data indicated that blood lead was a possible predictor of death rate (3). A NHANES III (1988-1994) mortality study suggested an association between blood lead concentration and risk of death from all causes and cancer among adults aged $\geq 40$ years with blood lead concentration of $5-9 \mu \mathrm{g} / \mathrm{dL}$ (16). Consistently, Cheung reported the correlation between blood lead concentration and cancer mortality using NHANES III data (14). However, Menke et al. similarly using NHANES III data revealed that blood lead at substantially low levels (below $10 \mu \mathrm{g} / \mathrm{dL}$ ) was correlated with elevated all-cause and cardiovascular death rate, but not cancer mortality (31). Inconsistent results were also reported in other general population-based studies. In the prospective Normative Aging Study, researchers showed bone lead levels, examined by K-shell X-ray fluorescence, were not correlated with cancer mortality, and were associated with a slight, but not significant, increase in all-cause and cardiovascular mortality (32). No association was found between blood lead concentration and cancer death rate in a cohort of 533 females enrolled in the study of Osteoporotic Fractures in U.S. from 1986 to 1988 (11). Because blood lead concentration of workers with occupational lead exposure is thought to be higher [often considerably over $80 \mu \mathrm{g} / \mathrm{dL}$ (33)] than that of general population (17), numerous occupational reports have examined the contribution of lead exposure to mortality of lead-exposed workers. However, the results from occupational studies are also controversial and inconclusive. In a cohort comprised 4,114 male lead workers, the all-cause mortality, mortalities due to liver or esophageal cancer were increased by lead exposure, as indicated by blood lead levels (18). Another cohort of 20,700 Finnish lead-exposed workers showed that high blood lead levels caused 1.4- and 1.8-fold raise of the overall cancer and lung cancer incidence, respectively (34). However, the effect of lead exposure on cancer mortality may be sex-specific as revealed by a cohort of 81,067 leadexposed workers in South Korea, where cancer mortality was increased only in female workers (17). By comparing lead levels in blood, breast normal, and tumor tissues, clinical evidence suggested that lead exposure was an important risk factor for breast lesions (35), and urinary lead levels were increased in severe breast carcinomas (36). Our analyses employed the most up-to-date NHANES and its mortality data, and used urinary lead, as the most non-invasive indicator for lead content estimation in the human body. The results supported a correlation between urinary lead concentration and cancer death rate in general population.

Our data indicated that the weighted percent of men in low urinary lead quartile $(\leq 0.40 \mu \mathrm{g} / \mathrm{L})$ and high urinary lead quartile $(>1.26 \mu \mathrm{g} / \mathrm{L})$ are approximately 32 and $65 \%$, respectively (Table 1). This is consistent with the idea that males are thought to have higher blood lead concentration than female in general because of higher lead exposure and blood hematocrit (8). Moreover, premenopausal women release bone lead more slowly than men, indicating a gender-specific discrepancy in lead metabolism (37). The gender-specific effect of lead on cancer mortality has been reported. Jemal et al. showed a significant spline dose-response result for high blood lead concentration (94th percentile) with a cancer mortality RRs of 2.4 compared with 12.5 th percentile only in female population (38). However, we observed significant associations $\left(P_{\text {trend }}<0.05\right)$ between urinary lead levels and cancer-specific mortality in both genders in sex-stratified adjusted Cox regression (Table S2 in Supplementary Material). It is of note that HR estimate compared to the upper quartile may be unstable in the sex-stratified analysis because of few cancer deaths in the lowest quartile of urinary lead ( $n=9$ for male; $n=13$ for female). Thus, most of our analyses combined data from both genders to increase statistical power.

Lead is expected to be a carcinogen in human according to occupational mortality and animal studies (16), and numerous mechanisms have been proposed for the carcinogenic effect of lead. One theory indicates the carcinogenic role of lead is through its capability to enhance cell proliferation (39). Experimental evidence shows that the proliferation of cultured bovine aortic smooth muscle cells can be induced by lead, but not other heavy metals such as zinc, copper, manganese, and nickel, and this stimulatory effect of lead on cell proliferation may be due to a calcium-dependent pathway considering that lead may mimic calcium in cellular metabolism (40). Moreover, lead has been reported to activate estrogen receptor- $\alpha$ and promote subsequent cell proliferation (41). Lead may also affect immune regulation and increase incidence of infectious diseases, autoimmune diseases, and cancer (42). By using cells isolated from lead-exposed individuals and unexposed healthy volunteers, Mishra et al. demonstrated that lead could target 

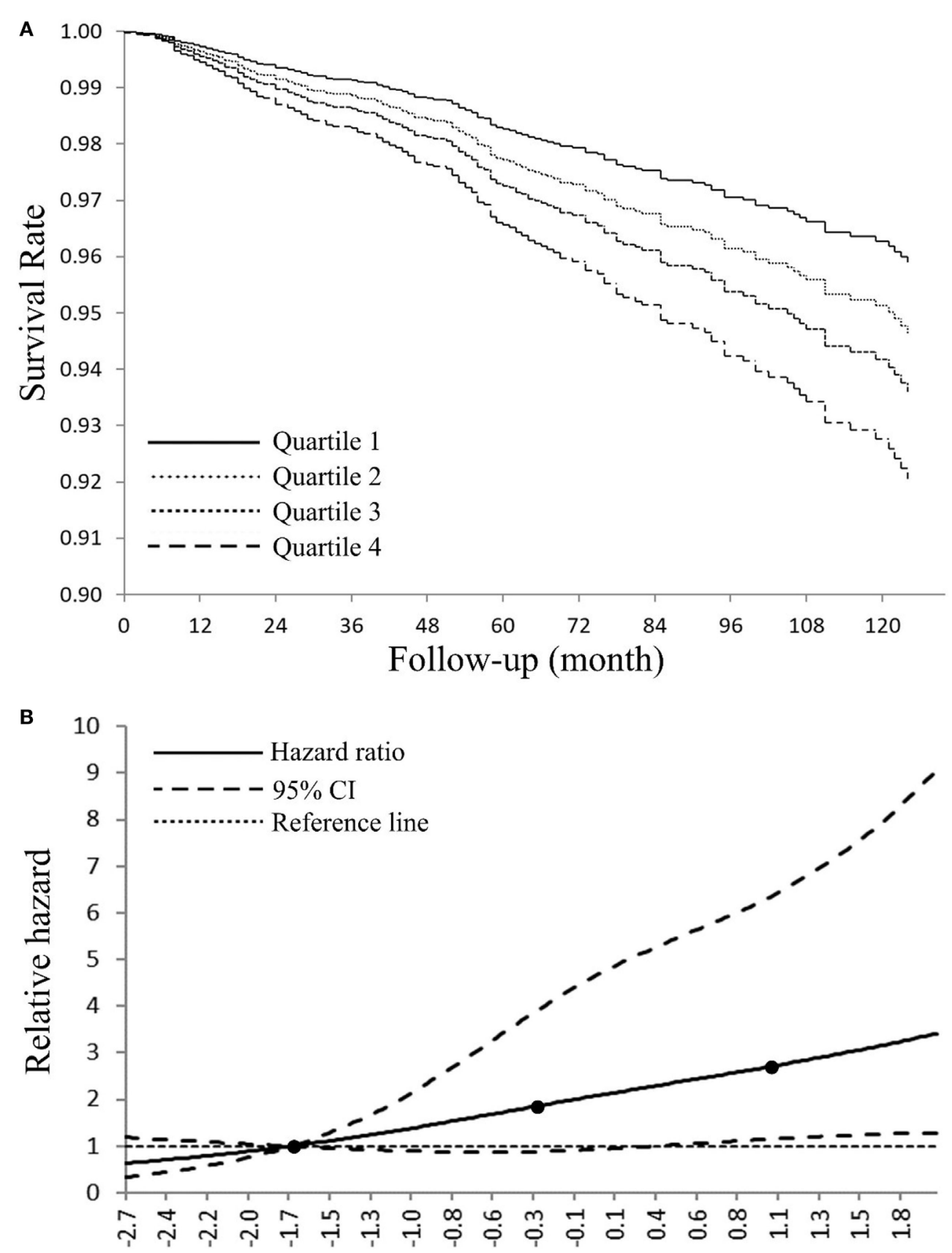

\section{Log transformed urinary lead}

FIGURE 2 | (A) Adjusted Kaplan-Meier survival curves for cumulative cancer mortality according to urinary lead quartile-National Health and Nutrition Examination Survey (NHANES) 1999-2010. Urinary lead quartiles: quartile 1: $\leq 0.40 \mu \mathrm{g} / \mathrm{L} ;$ quartile 2: 0.41-0.73 $\mu \mathrm{g} / \mathrm{L} ;$ quartile 3: 0.74-1.26 $\mu \mathrm{g} / \mathrm{L} ;$ quartile 4: >1.26 $\mu \mathrm{g} / \mathrm{L}$. (B) Adjusted dose-response association between log transformed urinary lead and risk for cancer-related death-NHANES 1999-2010. Log transformed urinary lead was coded using a restricted cubic splines function with three knots (black dots) located at 5th, 50th, and 95th percentiles of its distribution. Y-axis represents the adjusted hazard ratio for cancer mortality for any value of log transformed urinary lead compared with a referent level of fifth percentile of its distribution.

humoral and innate immune cells, thereby modulating immune system (42). Lead may also target various metalloproteins which represent around one-third of the proteome and serve as important regulators in physiological processes such as oxygen and electron transport and hydrolysis of amides and esters (43).
Dysregulation of metalloprotein has also been known to associate with pathological events, including invasive breast cancers, and better understanding the role of metal ions may help to illustrate the metal function in human carcinogenesis (36). Indeed, it has been reported that lead is involved in carcinogenesis by 
TABLE 4 | Hazard ratio for cancer mortality by level of nine urinary metalsNHANES 1999-2010.

\begin{tabular}{|c|c|c|c|c|}
\hline $\begin{array}{l}\text { Urinary metal } \\
\text { level ( } \mu \mathrm{g} / \mathrm{L})\end{array}$ & $N$ & cHR (95\% Cl) & aHR $(95 \% \mathrm{Cl})^{\mathrm{a}}$ & aHR $(95 \% \mathrm{Cl})^{\mathrm{b}}$ \\
\hline \multicolumn{5}{|l|}{ Barium } \\
\hline$\leq 0.62$ & 18 & 1.00 & 1.00 & 1.00 \\
\hline $0.63-1.23$ & 22 & $1.22(0.65-2.27)$ & $1.11(0.59-2.09)$ & $1.11(0.59-2.10)$ \\
\hline $1.24-2.33$ & 21 & $1.14(0.61-2.13)$ & $0.96(0.50-1.85)$ & $1.14(0.59-2.22)$ \\
\hline$>2.33$ & 16 & $0.87(0.44-1.71)$ & $0.70(0.34-1.42)$ & $0.79(0.39-1.63)$ \\
\hline$P$ for trend & & 0.66 & 0.27 & 0.56 \\
\hline \multicolumn{5}{|l|}{ Cadmium } \\
\hline$\leq 0.180$ & 11 & 1.00 & 1.00 & 1.00 \\
\hline $0.181-0.350$ & 11 & $0.97(0.42-2.23)$ & $1.13(0.47-2.72)$ & $0.88(0.36-2.14)$ \\
\hline $0.351-0.627$ & 14 & $1.23(0.56-2.72)$ & 1.55 (0.64-3.73) & $1.13(0.46-2.80)$ \\
\hline$>0.627$ & 41 & 3.59 (1.85-6.99) & $4.81(2.09-11.08)$ & $3.42(1.36-8.58)$ \\
\hline$P$ for trend & & $<0.01$ & $<0.01$ & $<0.01$ \\
\hline \multicolumn{5}{|l|}{ Cobalt } \\
\hline$\leq 0.200$ & 12 & 1.00 & 1.00 & 1.00 \\
\hline $0.201-0.324$ & 21 & $1.88(0.92-3.82)$ & $1.83(0.84-4.00)$ & $1.68(0.78-3.62)$ \\
\hline $0.325-0.501$ & 21 & $1.85(0.91-3.75)$ & 1.79 (0.79-4.06) & $1.61(0.71-3.67)$ \\
\hline$>0.501$ & 23 & $2.12(1.05-4.25)$ & $2.04(0.87-4.79)$ & $1.85(0.79-4.33)$ \\
\hline$P$ for trend & & 0.05 & 0.19 & 0.25 \\
\hline \multicolumn{5}{|l|}{ Cesium } \\
\hline$\leq 2.88$ & 11 & 1.00 & 1.00 & 1.00 \\
\hline $2.89-4.68$ & 25 & $2.40(1.18-4.88)$ & $2.06(0.93-4.55)$ & $1.74(0.79-3.83)$ \\
\hline 4.69-6.94 & 24 & 2.25 (1.10-4.58) & $1.80(0.75-4.33)$ & $1.63(0.67-3.93)$ \\
\hline$>6.94$ & 17 & $1.46(0.68-3.11)$ & $1.10(0.41-2.98)$ & $1.10(0.40-3.07)$ \\
\hline$P$ for trend & & 0.52 & 0.56 & 0.75 \\
\hline \multicolumn{5}{|l|}{ Molybdenum } \\
\hline$\leq 22.5$ & 12 & 1.00 & 1.00 & 1.00 \\
\hline $22.6-41.1$ & 20 & $1.70(0.83-3.48)$ & $1.62(0.76-3.46)$ & $1.42(0.66-3.06)$ \\
\hline $41.2-69.2$ & 24 & $2.02(1.01-4.04)$ & $1.87(0.85-4.16)$ & $1.83(0.82-4.07)$ \\
\hline$>69.2$ & 21 & $1.83(0.90-3.72)$ & $1.66(0.70-3.94)$ & $1.48(0.63-3.51)$ \\
\hline$P$ for trend & & 0.09 & 0.32 & 0.41 \\
\hline \multicolumn{5}{|l|}{ Lead } \\
\hline$\leq 0.38$ & 8 & 1.00 & 1.00 & 1.00 \\
\hline $0.39-0.68$ & 13 & $1.61(0.67-3.88)$ & 2.06 (0.80-5.29) & $1.45(0.57-3.71)$ \\
\hline $0.69-1.12$ & 22 & $2.61(1.16-5.86)$ & 3.75 (1.45-9.69) & $2.35(0.91-6.10)$ \\
\hline$>1.12$ & 34 & $3.70(1.71-8.00)$ & $5.74(2.17-15.19)$ & $3.15(1.17-8.48)$ \\
\hline$P$ for trend & & $<0.01$ & $<0.01$ & $<0.01$ \\
\hline \multicolumn{5}{|l|}{ Thallium } \\
\hline$\leq 0.086$ & 20 & 1.00 & 1.00 & 1.00 \\
\hline $0.087-0.146$ & 23 & $1.19(0.65-2.17)$ & $0.78(0.41-1.52)$ & $0.87(0.45-1.68)$ \\
\hline $0.147-0.226$ & 17 & $0.86(0.45-1.64)$ & $0.45(0.21-0.98)$ & $0.61(0.28-1.32)$ \\
\hline$>0.226$ & 17 & $0.81(0.42-1.54)$ & $0.36(0.16-0.84)$ & $0.68(0.29-1.57)$ \\
\hline$P$ for trend & & 0.35 & $<0.01$ & 0.27 \\
\hline \multicolumn{5}{|l|}{ Tungsten } \\
\hline$\leq 0.033$ & 18 & 1.00 & 1.00 & 1.00 \\
\hline $0.034-0.070$ & 24 & $1.29(0.70-2.37)$ & $1.10(0.58-2.08)$ & $1.12(0.60-2.12)$ \\
\hline $0.071-0.131$ & 19 & $1.23(0.64-2.34)$ & $0.98(0.49-1.97)$ & $0.95(0.48-1.91)$ \\
\hline$>0.131$ & 16 & $1.03(0.52-2.02)$ & 0.77 (0.36-1.64) & $0.81(0.38-1.74)$ \\
\hline$P$ for trend & & 0.96 & 0.42 & 0.49 \\
\hline \multicolumn{5}{|l|}{ Uranium } \\
\hline$\leq 0.0040$ & 24 & 1.00 & 1.00 & 1.00 \\
\hline $0.0041-0.0060$ & 13 & $1.26(0.64-2.47)$ & $1.11(0.55-2.23)$ & $1.17(0.58-2.36)$ \\
\hline $0.0061-0.0120$ & 23 & $1.39(0.79-2.47)$ & $1.19(0.64-2.19)$ & $1.40(0.75-2.62)$ \\
\hline$>0.0120$ & 17 & $1.05(0.56-1.96)$ & $0.86(0.43-1.70)$ & $1.07(0.52-2.18)$ \\
\hline$P$ for trend & & 0.67 & 0.77 & 0.68 \\
\hline
\end{tabular}

cHR, crude hazard ratio; aHR, adjusted hazard ratio; Cl, confidence interval; N, number of deaths; NHANES, National Health and Nutrition Examination Survey; BMI, body mass index; PIR, poverty income ratio.

a Model was adjusted for creatinine (a marker of urine dilution).

${ }^{b}$ Model was adjusted for creatinine, sex, age, education, race, PIR, BMI, smoking

status, alcohol-use status, diabetes status, and high blood pressure status.

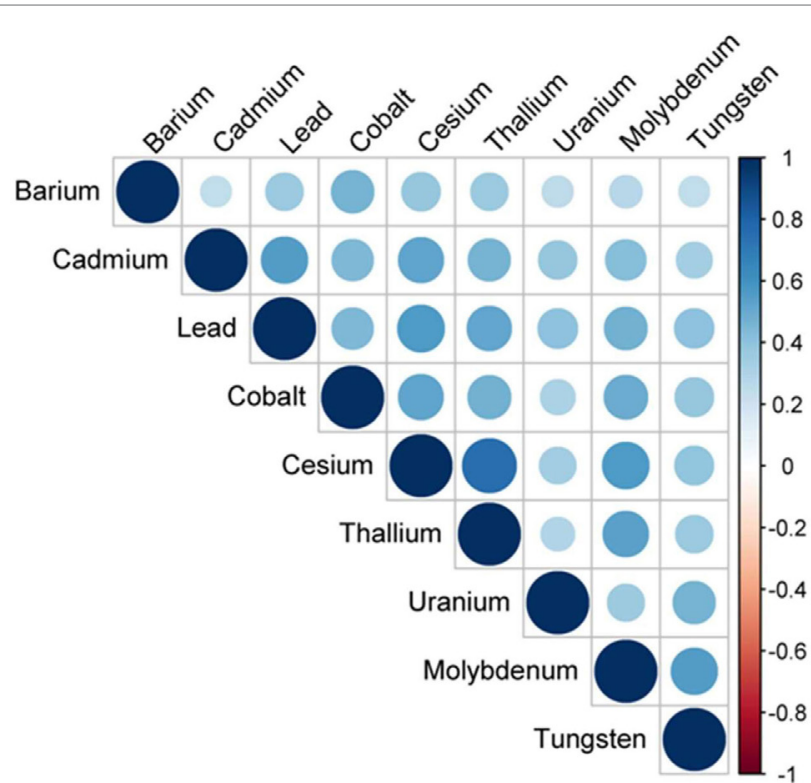

FIGURE 3 | Correlation structure of nine urinary metals - National Health and Nutrition Examination Survey 1999-2010. Circle size and color intensity were in proportion to the correlation coefficients. The legend in the right side of correlation structure indicated the correlation coefficients and their corresponding colors. The nine urinary metals were ordered by hierarchical clustering.

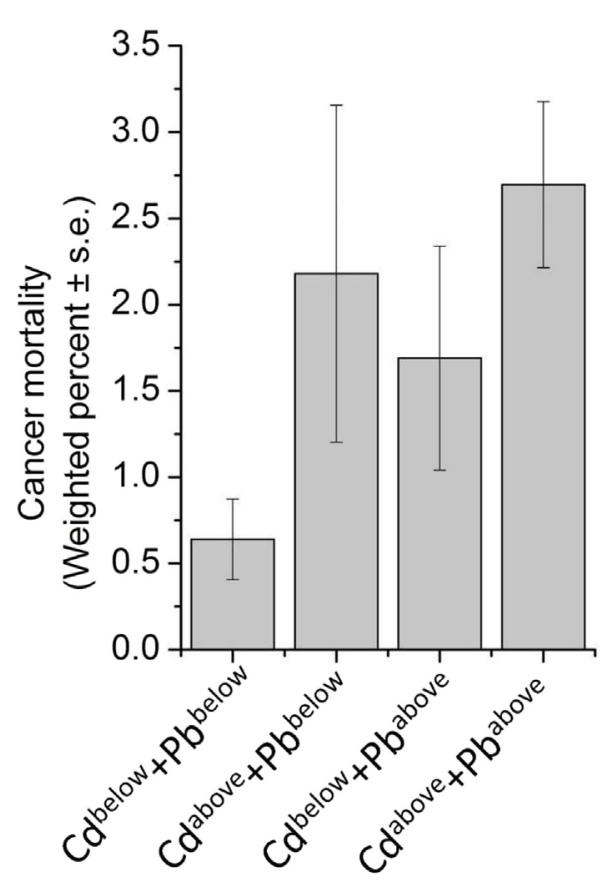

FIGURE 4 | Weighted prevalence of cancer mortality according to Cadmium $(\mathrm{Cd})$ and Lead $(\mathrm{Pb})$ levels - National Health and Nutrition Examination Survey 1999-2010. For Cd, below the median: $\leq 0.350 \mu \mathrm{g} / \mathrm{L}$; above the median: $>0.351 \mu \mathrm{g} / \mathrm{L}$. For $\mathrm{Pb}$, below the median: $\leq 0.68 \mu \mathrm{g} / \mathrm{L}$; above the median: $>0.69 \mu \mathrm{g} / \mathrm{L}$. 
modifying zinc level or replacing zinc in $\mathrm{Zn}$-containing proteins (44). Indirect mechanisms of lead-related carcinogenesis such as production of free radicals and inhibition of DNA repair have been proposed (44). Siddiqui et al. reported that lead exposure induced oxidative damage caused by reactive oxygen species, thereby increasing the risk of breast lesions (35). As weak carcinogen, lead inhibits DNA repair and acts synergistically with other mutagens (45). It has been known that lead antagonizes selenium and minimizes its anti-carcinogenic effect, thereby increasing the risk for developing breast cancer (46). The effect of lead exposure on diseases may be subtle, and other genetic and environmental factors may also be involved (3). For instance, delta-aminolevulinic acid dehydratase $(A L A D)$, a genitourinary cancer-related gene, is a target of lead. Inhibition of ALAD enzyme may diminish its role in heme biosynthesis and preventing protein degradation by $26 \mathrm{~S}$ proteasome (44). Furthermore, the G177C genetic polymorphism of ALAD alters lead toxicokinetics and adverse effects of lead exposure, and $\mathrm{ALAD}{ }^{\mathrm{CG} / \mathrm{CC}}$ genotype is associated with reduced death rate from all causes and from cancer (47). Thus, lead may promote carcinogenesis in human through multiple mechanisms.

Cancer is the second most common death inducer in many countries, and one of the most significant contributors to mortality worldwide. With the improvement in prevention and treatment of heart diseases, cancer is likely to become the number-one killer in the near further (48). Thus, detection early stage cancer is crucial to minimize tumor upstaging and increase patient survival rate, and prediction of further trends in cancer mortality may provide important implication for healthcare planning. Study of metal within a biological system may help people better understand the essential roles of metal in pathophysiology and provide a novel approach for disease detection and diagnosis (36). Indeed, urinary metal concentration has been served as biomarker for numerous physiological and pathological conditions in human, including thyroid function (49), renal dysfunction (50), and cardiac disease (51). Recently, an "omics" approach to simultaneously quantify 22 urinary metals (as metallomics) is established to facilitate personalized cancer screening and prevention, which reveals the significantly higher levels of lead in urine from breast cancer patients, indicating that urinary lead may serve as potential breast cancer biomarker (36). By employing NHANES and its mortality data, we reported 6.60-fold increase of cancer-specific mortality with high urinary lead levels $(>1.26 \mu \mathrm{g} / \mathrm{L})$ when comparing with those with low urinary lead levels $(\leq 0.40 \mu \mathrm{g} / \mathrm{L})$ (Table 3). This consistently introduces urinary lead as a non-invasive indicator to predict cancer-related mortality. Considering that lead exposure may co-occur with other toxic metals, we screened a panel of nine urinary metals and found any pair of these metals was positively correlated $(P<0.01)$ (Figure 3). Moreover, the association between urinary cadmium levels and cancer mortality was identified $\left(P_{\text {trend }}<0.01\right)$ (Table 4). Cadmium is a known human carcinogen as classified by IARC. Similar with lead, cadmium is also stored in bone (52). Due to its long biological half-life in human, urinary cadmium has been assumed as a biomarker for long-term cadmium exposure in various studies (53-56). More specifically, urinary cadmium is reported to be associated with cancer-caused mortality in general U.S. population enrolled in NHANES III (1988-1994) $(54,57)$, and American Indians participated in the Strong Heart Study (1989-1991) (56). Numerous possible mechanisms of carcinogenesis induced by cadmium have been proposed. Cadmium has been reported to modulate cellular proliferation and induce apoptosis. Indirect effects of cadmium also lead to oxidative stress and DNA damage (58). Moreover, cadmium reduces the capability for gene replacement in cells, thereby increasing the level of genetic instability (59). Cadmium may also serve as potent metallohormone and promote hormonedependent carcinogenesis (60). For urinary cadmium and lead, their correlation has been reported (61). Thus, we further adjusted log transformed urinary cadmium concentration as an independent variable to exclude the possibility that urinary lead levels serve as a surrogate marker of urinary cadmium levels and are of no separate significance. The results consistently showed that urinary lead levels were associated with cancer mortality $\left(P_{\text {trend }}<0.05\right)$, indicating urinary lead levels as an independent predictor of cancer mortality. Furthermore, RR-based measurement between urinary cadmium and lead on the additive scale suggests that participants with both cadmium and lead above the median showed a relatively higher risk for cancer mortality (Figure 4). However, these analyses were based on 77 deaths due to cancer, and further studies with larger sample size are needed to verify our findings.

There are three ways to estimate human lead content: bone lead, blood lead, and urinary lead. Human skeleton deposits 95\% of absorbed lead and serves as an endogenous reservoir for years after lead exposure (11). Thus, bone lead levels may provide a better indicator of cumulative lead exposure due to its longer halflife (62). Blood lead levels have been widely applied to estimate human lead exposure (63) while urinary lead may also be used for the assessment of lead exposed occupationally $(64,65)$ or environmentally (66). Indeed, urinary lead levels have been reported to be associated with bone health (67), toxocariasis infection in children (68) and asthma (69). Considering that urinary lead concentration may be relatively unstable compared to blood lead concentration, correlation analyses were performed, and the results showed moderately strong positive relationship between urinary and blood lead concentration in the analysis populations (Figure 1). Moreover, urinary lead is deemed as the most non-invasive and accessible way for lead measurement in human and is thus employed in this study. Current study has several limitations. First, site-specific cancer mortality is not provided because information of mortality due to specific type of cancer is not publicly available in NHANES (1999-2010) linked mortality file in order to protect the confidentiality of the participants. Considering the few total cancer deaths in the lowest quartile of urinary lead ( $n=22$ ) (Table 3), it is unlikely to have enough statistical power to identify associations between urinary lead levels and individual subtypes of cancer mortality because numbers of deaths from these cancers will be smaller (56). Moreover, this study has not illustrated the effects of urinary lead levels on cancer incidence and cancer survival, both of which contribute to cancer mortality. In addition, 10-year survival was calculated in our analyses (Figure 2A), but very few subjects were expected 
to have a follow-up of 10 years or longer (the median follow-up was 66 months). Furthermore, it is difficult to differentiate the acute and chronic effect of lead in investigations that only employ blood/urinary lead concentrations to represent exposure (62). Exposure misclassification serves as another potential limitation of this study, in which a single spot urine sample was employed to classify lead exposure. Both smoking status and alcohol-use status were assessed with a single question that could not distinguish light smokers/drinkers from heavy ones, which might be potential information bias. Despite these limitations, our study has several strengths. NHANES collected numerous health exposures and outcomes under an extensive quality control, and the survey data are generalizable to non-institutional civilian U.S. population. By employing the most up-to-date NHANES and its mortality data, our analyses screened nine urinary metals, and verified the association between urinary cadmium levels and cancer mortality. Moreover, this is the first study to demonstrate urinary lead concentration as an independent predictor of cancer mortality in general population.

\section{CONCLUSION}

A positive correlation between urinary lead levels and cancer mortality was observed in the U.S. general population. Although further investigations are needed to illustrate the mechanisms, findings from the present study suggest a potential role of lead in cancer mortality, and a comprehensive understanding of lead content may help to discover novel diagnostic, prognostic, and therapeutic approaches for malignant neoplasms. Understanding of lead exposure routes such as dietary intake and environmental exposure may provide useful information on prevention of lead exposure, and its adverse effects.

\section{REFERENCES}

1. Hernberg S. Lead poisoning in a historical perspective. Am J Ind Med (2000) 38:244-54. doi:10.1002/1097-0274(200009)38:3<244::AID-AJIM3>3.0.CO;2-F

2. Lead Toxicity What Are the Physiologic Effects of Lead Exposure? (2017). Available from: https://www.atsdr.cdc.gov/csem/csem.asp?csem $=7 \& p o=10$ (accessed January 5, 2017).

3. Lustberg M, Silbergeld E. Blood lead levels and mortality. Arch Intern Med (2002) 162:2443-9. doi:10.1001/archinte.162.21.2443

4. Needleman HL. The removal of lead from gasoline: historical and personal reflections. Environ Res (2000) 84:20-35. doi:10.1006/enrs.2000.4069

5. Pirkle JL, Brody DJ, Gunter EW, Kramer RA, Paschal DC, Flegal KM, et al. The decline in blood lead levels in the United States. The National Health and Nutrition Examination Surveys (NHANES). JAMA (1994) 272:284-91. doi:10.1001/jama.272.4.284

6. Muntner P, Menke A, Desalvo KB, Rabito FA, Batuman V. Continued decline in blood lead levels among adults in the United States: the National Health and Nutrition Examination Surveys. Arch Intern Med (2005) 165:2155-61. doi:10.1001/archinte.165.18.2155

7. Wilker E, Korrick S, Nie LH, Sparrow D, Vokonas P, Coull B, et al. Longitudinal changes in bone lead levels: the VA Normative Aging Study. J Occup Environ Med (2011) 53:850-5. doi:10.1097/JOM.0b013e31822589a9

8. Vahter M, Akesson A, Liden C, Ceccatelli S, Berglund M. Gender differences in the disposition and toxicity of metals. Environ Res (2007) 104:85-95. doi:10.1016/j.envres.2006.08.003

9. Mejare M, Bulow L. Metal-binding proteins and peptides in bioremediation and phytoremediation of heavy metals. Trends Biotechnol (2001) 19:67-73. doi:10.1016/S0167-7799(00)01534-1

\section{AVAILABILITY OF DATA AND MATERIAL}

The data used in this study are from NHANES 1999-2010 and corresponding Mortality Follow-Up Study. Data are publicly available and can be downloaded from NHANES website: http:// www.cdc.gov/nchs/nhanes.htm.

\section{ETHICS STATEMENT}

Data analyzed in this study were obtained from NHANES. Protocols involved were approved by the National Center for Health Statistics (NCHS) Research Ethics Review Board (ERB), and consent from all participants was documented.

\section{AUTHOR CONTRIBUTIONS}

SL designed the study and drafted the manuscript. SL, JW, and BZ carried out the statistical analysis. YL, TL, YS, GS, and LD critically reviewed the manuscript. All the authors read and approved the final manuscript.

\section{FUNDING}

This study is supported by the National Natural Science Foundation of China (Grant No. 81703942) and BUCM research program (to SL).

\section{SUPPLEMENTARY MATERIAL}

The Supplementary Material for this article can be found online at https://www.frontiersin.org/articles/10.3389/fonc.2018.00242/ full\#supplementary-material.

10. Jain NB, Potula V, Schwartz J, Vokonas PS, Sparrow D, Wright RO, et al. Lead levels and ischemic heart disease in a prospective study of middle-aged and elderly men: the VA Normative Aging Study. Environ Health Perspect (2007) 115:871-5. doi:10.1289/ehp.9629

11. Khalil N, Wilson JW, Talbott EO, Morrow LA, Hochberg MC, Hillier TA, et al. Association of blood lead concentrations with mortality in older women: a prospective cohort study. Environ Health (2009) 8:15. doi:10.1186/ 1476-069X-8-15

12. Park SK, Mukherjee B, Xia X, Sparrow D, Weisskopf MG, Nie H, et al. Bone lead level prediction models and their application to examine the relationship of lead exposure and hypertension in the Third National Health and Nutrition Examination Survey. J Occup Environ Med (2009) 51:1422-36. doi:10.1097/ JOM.0b013e3181bf6c8d

13. Kim R, Rotnitsky A, Sparrow D, Weiss S, Wager C, Hu H. A longitudinal study of low-level lead exposure and impairment of renal function. The Normative Aging Study. JAMA (1996) 275:1177-81.

14. Cheung MR. Blood lead concentration correlates with all cause, all cancer and lung cancer mortality in adults: a population based study. Asian Pac J Cancer Prev (2013) 14:3105-8. doi:10.7314/APJCP.2013.14.5.3105

15. International Agency for Research on Cancer. Inorganic and organic lead compounds. IARC Monograph on the Evaluation of Carcinogenic Risks to Humans. Vol. 87, Lyon: IARC (2006). p. 378.

16. Schober SE, Mirel LB, Graubard BI, Brody DJ, Flegal KM. Blood lead levels and death from all causes, cardiovascular disease, and cancer: results from the NHANES III mortality study. Environ Health Perspect (2006) 114:1538-41. doi:10.1289/ehp.9123

17. Kim MG, Ryoo JH, Chang SJ, Kim CB, Park JK, Koh SB, et al. Blood lead levels and cause-specific mortality of inorganic lead-exposed workers in 
South Korea. PLoS One (2015) 10:e0140360. doi:10.1371/journal.pone. 0140360

18. Gwini S, Macfarlane E, Del Monaco A, Mclean D, Pisaniello D, Benke GP, et al. Cancer incidence, mortality, and blood lead levels among workers exposed to inorganic lead. Ann Epidemiol (2012) 22:270-6. doi:10.1016/j. annepidem.2012.01.003

19. Li S, Wen X. Seropositivity to herpes simplex virus type 2, but not type 1 is associated with cervical cancer: NHANES (1999-2014). BMC Cancer (2017) 17:726. doi:10.1186/s12885-017-3734-2

20. Mazidi M, Rezaie P, Covic A, Malyszko J, Rysz J, Kengne AP, et al. Telomere attrition, kidney function, and prevalent chronic kidney disease in the United States. Oncotarget (2017) 8:80175-81. doi:10.18632/oncotarget.20706

21. Centers for Disease Control and Prevention (CDC). National Center for Health Statistics (NCHS). National Health and Nutrition Examination Survey Data. Hyattsville, MD, USA: Department of Health and Human Services, Centers for Disease Control and Prevention (2016). Available from: https://www.cdc.gov/nchs/nhanes.htm (Accessed: June 23, 2018).

22. Centers for Disease Control and Prevention (CDC). National Center for Health Statistics (NCHS). National Health and Nutrition Examination Survey Laboratory Protocol. Hyattsville, MD, USA: Department of Health and Human Services, Centers for Disease Control and Prevention (2016). Available from: https://www.cdc.gov/nchs/data/nhanes/nhanes_11_12/2011-12_Laboratory_ Procedures_Manual.pdf (Accessed: June 23, 2018).

23. Ikeda M, Ezaki T, Tsukahara T, Moriguchi J, Furuki K, Fukui Y, et al. Bias induced by the use of creatinine-corrected values in evaluation of beta2-microgloblin levels. Toxicol Lett (2003) 145:197-207. doi:10.1016/ S0378-4274(03)00320-5

24. Barr DB, Wilder LC, Caudill SP, Gonzalez AJ, Needham LL, Pirkle JL. Urinary creatinine concentrations in the U.S. population: implications for urinary biologic monitoring measurements. Environ Health Perspect (2005) 113:192-200. doi:10.1289/ehp.7337

25. Scinicariello F, Feroe AG, Attanasio R. Urinary phthalates and leukocyte telomere length: an analysis of NHANES 1999-2002. EBioMedicine (2016) 6:96-102. doi:10.1016/j.ebiom.2016.02.027

26. Adams SV, Newcomb PA. Cadmium blood and urine concentrations as measures of exposure: NHANES 1999-2010. J Expo Sci Environ Epidemiol (2014) 24:163-70. doi:10.1038/jes.2013.55

27. Afriyie-Gyawu E, Ifebi E, Ampofo-Yeboah A, Kyte B, Shrestha S, Zhang J. Serum folate levels and fatality among diabetic adults: A 15 -y follow-up study of a national cohort. Nutrition (2016) 32:468-73. doi:10.1016/j.nut.2015.10.021

28. Allison PD. Survival Analysis Using SAS. A Practical Guide. Cary, NC: SAS Publishing (1995).

29. Chappell R. Competing risk analyses: how are they different and why should you care? Clin Cancer Res (2012) 18:2127-9. doi:10.1158/1078-0432. CCR-12-0455

30. Desquilbet L, Mariotti F. Dose-response analyses using restricted cubic spline functions in public health research. Stat Med (2010) 29:1037-57. doi:10.1002/ sim. 3841

31. Menke A, Muntner P, Batuman V, Silbergeld EK, Guallar E. Blood lead below $0.48 \mathrm{micromol} / \mathrm{L}$ (10 microg/dL) and mortality among US adults. Circulation (2006) 114:1388-94. doi:10.1161/CIRCULATIONAHA.106.628321

32. Weisskopf MG, Jain N, Nie H, Sparrow D, Vokonas P, Schwartz J, et al. A prospective study of bone lead concentration and death from all causes, cardiovascular diseases, and cancer in the Department of Veterans Affairs Normative Aging Study. Circulation (2009) 120:1056-64. doi:10.1161/ CIRCULATIONAHA.108.827121

33. Malcolm D, Barnett HA. A mortality study of lead workers 1925-76. Br J Ind Med (1982) 39:404-10.

34. Anttila A, Heikkila P, Pukkala E, Nykyri E, Kauppinen T, Hernberg S, et al. Excess lung cancer among workers exposed to lead. Scand J Work Environ Health (1995) 21:460-9. doi:10.5271/sjweh.62

35. Siddiqui MK, Jyoti, Singh S, Mehrotra PK, Singh K, Sarangi R. Comparison of some trace elements concentration in blood, tumor free breast and tumor tissues of women with benign and malignant breast lesions: an Indian study. Environ Int (2006) 32:630-7. doi:10.1016/j.envint.2006.02.002

36. Burton C, Dan Y, Donovan A, Liu K, Shi H, Ma Y, et al. Urinary metallomics as a novel biomarker discovery platform: breast cancer as a case study. Clin Chim Acta (2016) 452:142-8. doi:10.1016/j.cca.2015.11.014
37. Popovic M, Mcneill FE, Chettle DR, Webber CE, Lee CV, Kaye WE. Impact of occupational exposure on lead levels in women. Environ Health Perspect (2005) 113:478-84. doi:10.1289/ehp.7386

38. Jemal A, Graubard BI, Devesa SS, Flegal KM. The association of blood lead level and cancer mortality among whites in the United States. Environ Health Perspect (2002) 110:325-9. doi:10.1289/ehp.02110325

39. Calabrese EJ, Baldwin LA. Lead-induced cell proliferation and organspecific tumorigenicity. Drug Metab Rev (1992) 24:409-16. doi:10.3109/ 03602539208996299

40. Fujiwara Y, Kaji T, Yamamoto C, Sakamoto M, Kozuka H. Stimulatory effect of lead on the proliferation of cultured vascular smooth-muscle cells. Toxicology (1995) 98:105-10. doi:10.1016/0300-483X(94)02984-3

41. Martin MB, Reiter R, Pham T, Avellanet YR, Camara J, Lahm M, et al. Estrogen-like activity of metals in MCF-7 breast cancer cells. Endocrinology (2003) 144:2425-36. doi:10.1210/en.2002-221054

42. Mishra KP, Chauhan UK, Naik S. Effect of lead exposure on serum immunoglobulins and reactive nitrogen and oxygen intermediate. Hum Exp Toxicol (2006) 25:661-5. doi:10.1177/0960327106070453

43. Tainer JA, Roberts VA, Getzoff ED. Metal-binding sites in proteins. Curr Opin Biotechnol (1991) 2:582-91. doi:10.1016/0958-1669(91)90084-I

44. Neslund-Dudas C, Levin AM, Rundle A, Beebe-Dimmer J, Bock CH, Nock NL, et al. Case-only gene-environment interaction between ALAD tagSNPs and occupational lead exposure in prostate cancer. Prostate (2014) 74:637-46. doi:10.1002/pros.22781

45. Steenland K, Boffetta P. Lead and cancer in humans: where are we now? Am J Ind Med (2000) 38:295-9. doi:10.1002/1097-0274(200009)38:3<295::AIDAJIM8 $>3.0 . \mathrm{CO} ; 2-\mathrm{L}$

46. Alatise OI, Schrauzer GN. Lead exposure: a contributing cause of the current breast cancer epidemic in Nigerian women. Biol Trace Elem Res (2010) 136:127-39. doi:10.1007/s12011-010-8608-2

47. van Bemmel DM, Li Y, Mclean J, Chang MH, Dowling NF, Graubard B, et al. Blood lead levels, ALAD gene polymorphisms, and mortality. Epidemiology (2011) 22:273-8. doi:10.1097/EDE.0b013e3182093f75

48. Ma X, Yu H. Global burden of cancer. Yale J Biol Med (2006) 79:85-94.

49. Yorita Christensen KL. Metals in blood and urine, and thyroid function among adults in the United States 2007-2008. Int J Hyg Environ Health (2013) 216:624-32. doi:10.1016/j.ijheh.2012.08.005

50. Karakaya A, Karaaslan Z, Duydu Y, Yücesoy B, Oflaz G, Köse SK. Association between urinary indicators of renal dysfunction and metal concentrations in workers chronically co-exposed to cadmium, zinc and lead. Biomarkers (2001) 6:351-6. doi:10.1080/13547500110045761

51. Saulnier PJ, Gand E, Ragot S, Bankir L, Piguel X, Fumeron F, et al. Urinary sodium concentration is an independent predictor of all-cause and cardiovascular mortality in a type 2 diabetes cohort population. J Diabetes Res (2017) 2017:5327352. doi:10.1155/2017/5327352

52. Bocio A, Nadal M, Garcia F, Domingo JL. Monitoring metals in the population living in the vicinity of a hazardous waste incinerator: concentrations in autopsy tissues. Biol Trace Elem Res (2005) 106:41-50. doi:10.1385/BTER:106:1:041

53. Menke A, Muntner P, Silbergeld EK, Platz EA, Guallar E. Cadmium levels in urine and mortality among U.S. adults. Environ Health Perspect (2009) 117:190-6. doi:10.1289/ehp.11236

54. Adams SV, Passarelli MN, Newcomb PA. Cadmium exposure and cancer mortality in the Third National Health and Nutrition Examination Survey cohort. Occup Environ Med (2012) 69:153-6. doi:10.1136/oemed-2011-100111

55. Hyder O, Chung M, Cosgrove D, Herman JM, Li Z, Firoozmand A, et al. Cadmium exposure and liver disease among US adults. J Gastrointest Surg (2013) 17:1265-73. doi:10.1007/s11605-013-2210-9

56. Garcia-Esquinas E, Pollan M, Tellez-Plaza M, Francesconi KA, Goessler W, Guallar E, et al. Cadmium exposure and cancer mortality in a prospective cohort: the strong heart study. Environ Health Perspect (2014) 122:363-70. doi:10.1289/ehp.1306587

57. Lin YS, Caffrey JL, Lin JW, Bayliss D, Faramawi MF, Bateson TF, et al. Increased risk of cancer mortality associated with cadmium exposures in older Americans with low zinc intake. J Toxicol Environ Health A (2013) 76:1-15. d oi:10.1080/15287394.2012.722185

58. Bertin G, Averbeck D. Cadmium: cellular effects, modifications of biomolecules, modulation of DNA repair and genotoxic consequences (a review). Biochimie (2006) 88:1549-59. doi:10.1016/j.biochi.2006.10.001 
59. Jin YH, Clark AB, Slebos RJ, Al-Refai H, Taylor JA, Kunkel TA, et al. Cadmium is a mutagen that acts by inhibiting mismatch repair. Nat Genet (2003) 34:326-9. doi:10.1038/ng1172

60. Byrne C, Divekar SD, Storchan GB, Parodi DA, Martin MB. Cadmium - a metallohormone? Toxicol Appl Pharmacol (2009) 238:266-71. doi:10.1016/j. taap.2009.03.025

61. Lewis SC, Forney RB. Correlation of lead and cadmium in human urine. J Forensic Sci (1976) 21:150-3. doi:10.1520/JFS10347J

62. Hu H, Rabinowitz M, Smith D. Bone lead as a biological marker in epidemiologic studies of chronic toxicity: conceptual paradigms. Environ Health Perspect (1998) 106:1-8. doi:10.1289/ehp.981061

63. Schwartz BS, Hu H. Adult lead exposure: time for change. Environ Health Perspect (2007) 115:451-4. doi:10.1289/ehp.9782

64. Fukui Y, Miki M, Ukai H, Okamoto S, Takada S, Higashikawa K, et al. Urinary lead as a possible surrogate of blood lead among workers occupationally exposed to lead. Int Arch Occup Environ Health (1999) 72:516-20. doi:10.1007/ s004200050409

65. Moreira Mde F, Neves EB. [Use of urine lead level as an exposure indicator and its relationship to blood lead]. Cad Saude Publica (2008) 24:2151-9. doi:10.1590/S0102-311X2008000900021

66. Higashikawa K, Zhang ZW, Shimbo S, Moon CS, Watanabe T, Nakatsuka H, et al. Correlation between concentration in urine and in blood of cadmium and lead among women in Asia. Sci Total Environ (2000) 246:97-107. doi:10.1016/ S0048-9697(99)00415-5
67. Tsai TL, Pan WH, Chung YT, Wu TN, Tseng YC, Liou SH, et al. Association between urinary lead and bone health in a general population from Taiwan. J Expo Sci Environ Epidemiol (2016) 26:481-7. doi:10.1038/jes. 2015.30

68. Farmer A, Beltran T, Choi YS. Prevalence of Toxocara species infection in the U.S.: results from the National Health and Nutrition Examination Survey, 2011-2014. PLoS Negl Trop Dis (2017) 11:e0005818. doi:10.1371/journal. pntd.0005818

69. Huang X, Xie J, Cui X, Zhou Y, Wu X, Lu W, et al. Association between concentrations of metals in urine and adult asthma: a case-control study in Wuhan, China. PLoS One (2016) 11:e0155818. doi:10.1371/journal. pone. 0155818

Conflict of Interest Statement: The authors declare that the research was conducted in the absence of any commercial or financial relationships that could be construed as a potential conflict of interest.

Copyright $\odot 2018 \mathrm{Li}$, Wang, Zhang, Liu, Lu, Shi, Shan and Dong. This is an openaccess article distributed under the terms of the Creative Commons Attribution License (CC BY). The use, distribution or reproduction in other forums is permitted, provided the original author(s) and the copyright owner are credited and that the original publication in this journal is cited, in accordance with accepted academic practice. No use, distribution or reproduction is permitted which does not comply with these terms. 